IISSN: 1130-3743 - ISSN electrónico: 2386-5660

DOI: http://dx.doi.org/10.14201/teoredu20152727189

\title{
LA INELUDIBLE REVOLUCIÓN DE LA MENTE: REFLEXIONES SOBRE EDUCACIÓN A PARTIR DE EL ARTE DE VIVIR DE JIDDU KRISHNAMURTI
}

\author{
The Inevitable Revolution of Mind: Reflections on \\ Education from $\mathrm{El}$ arte de vivir by Jiddu Krishnamurti
}

\section{L'inévitable révolution de l'esprit: Réflexions sur l'éducation à partir de $\mathrm{El}$ arte de vivir de Jiddu Krishnamurti}

\section{Diego LuNA}

Universidad de Sevilla. Facultad de Filosofía. Departamento de Estética e Historia de la Filosofía. C/ Camilo José Cela, s/n. 41018 Sevilla. dielundel@gmail.com

Fecha de recepción: marzo de 2015

Fecha de aceptación: junio de 2015

Biblid [(1130-3743) 27, 2-2015, 71-89]

RESUMEN

En el presente trabajo se proponen una serie de consideraciones sobre educación a partir de las ideas planteadas en la obra El arte de vivir (Life Ahead: On Learning and the Search of Meaning en su edición original en inglés) del pensador indio Jiddu Krishnamurti. Para ello se establecerá, por una parte, una síntesis conceptual de las ideas del autor en relación a los problemas sociales con los que se enfrenta la educación actualmente y, por otra, se reflexionará sobre el posible lugar que estas ocupan dentro de un marco histórico general del pensamiento educativo.

Palabras clave: Jiddu Krishnamurti; educación transpersonal; mente; emoción. 


\section{SUMMARY}

In this paper, several considerations about education are proposed after the ideas raised in Jiddu Krishnamurti's El arte de vivir (Life Abead: On Learning and the Search of Meaning in the original English edition) by Jiddu Krishnamurti. In order to do so, a conceptual synthesis of his ideas concerning social issues dealt with by education today will be set on the one hand. On the other, a reflection will be carried out so as to determine whether his ideas fit into a general historical framework of educational thought.

Key words: Jiddu Krishnamurti; transpersonal education; mind; emotion.

\section{SOMMAIRE}

Dans cet article, nous émettrons un certain nombre de considérations sur l'éducation à partir des idées dévelopées dans le livre L'Art de Vivre (Life Ahead: On Learning and the Search of learning dans l'édition originale en anglais) du philosophe indien Jiddu Krishnamurti. Pour ce faire, nous proposerons tout d'abord une synthèse conceptuelle des idées autour des problèmes sociaux auxquels l'éducation doit faire face aujourd'hui. Nous réflechirons enfin sur la possible insertion de ses propositions dans un contexte historique général de la pensée éducative.

Mots clés: Jiddu Krishnamurti; éducation transpersonnelle; esprit; émotion.

\section{INTRODUCCIÓN: LOS PROBLEMAS DE LA EDUCACIÓN ACTUAL}

Escucha atentamente y lo descubrirás. Estamos examinando la pregunta, no estamos buscando la respuesta (Krishnamurti, 1993, 124).

Muchas son las voces que de modo riguroso han venido cuestionando desde hace algunas décadas cierto paradigma educativo firmemente asentado en nuestra cultura occidental, hoy global. Posiciones cuyo origen, desde una perspectiva filosófica general, podríamos ubicar dentro de aquella etapa en la que los grandes metarrelatos de legitimación del saber, utilizando los términos de Lyotard (2012), entraron en una supuesta crisis de credibilidad. Un planteamiento que, de entrada, bien debiera evidenciar una necesidad prioritaria de identificar cómo fueron -O son- exactamente las herramientas y los medios que con el tiempo han permitido dichas legitimaciones o, en otras palabras, de qué manera se hubieron consolidado y perpetuado algunos conjuntos de ideas que aquí en Occidente, al menos hasta la segunda mitad del siglo Xx, conformaron durante siglos un determinado e incontestable funcionamiento del mundo y una muy definida cosmovisión hegemónica. 
No debe sorprender, por tanto, el hecho de que desde entonces hayan sido muchas esas voces insumisas (Freire, Neill, Illich, Naranjo, etc.) que, conscientes de la importancia del medio educativo en la configuración básica y en la (auto)legitimación de los sistemas sociopolíticos, se han preguntado si de verdad nuestro modo de educar a las generaciones futuras era -o es- el más adecuado.

Dentro de este marco teórico crítico respecto al modelo educativo tradicional, campo en el que aquí nos moveremos, las ideas de Jiddu Krishnamurti (1895-1986) representan, según creemos, una propuesta única por su carácter, no solo alternativo, sino revolucionario respecto al modelo existente; este último, prácticamente el mismo que el que trajese consigo la Revolución Industrial a partir del siglo XVIII. Un modelo, recordemos, cuyos objetivos eran claros: por un lado, alfabetizar y preparar a los empleados de fábrica para que repitieran una y otra vez las mismas funciones y, por otro, que estos mismos individuos fuesen súbditos ejemplares de unos nuevos Estados-nacionales y unas viejas monarquías cada vez más desprestigiadas. Dos necesidades que fijaron el diseño de un tipo de escuela lineal y estática, cuyos rasgos esenciales han perdurado hasta nuestros días disueltos en el nuevo dogma del llamado "progreso científico-tecnológico". Un proyecto que, lejos de fomentar el pensamiento crítico y autónomo, aquella ilustrada-romántica "mayoría de edad" kantiana, se sigue ciñendo sorprendentemente a un enfoque puramente instrumental y acumulativo de datos: un profesor se limita a dictar unos conocimientos determinados a unos alumnos que deben aprenderlos, siguiendo una lógica competitiva y meritocrática incapaz de inspirar una mejora real de la situación vital del individuo.

Frente a esta situación, la población, por su parte, padece la incapacidad de percibir esta como un resultado más de la exitosa manipulación ideológica; un proceso capaz de llegar incluso a desarticular con el tiempo los conocimientos ya adquiridos. En este contexto, «el logro académico - dicen Brunet y Altaba- constituye una señal de la capacidad de adaptación social y del futuro éxito profesional del alumnado» (2010, 242), siendo esta fórmula del «logro académico» y sus implicaciones, sin embargo, la manera en que la educación lleva siglos reprimiendo los talentos y habilidades de muchos estudiantes y, por consiguiente, extinguiendo las motivaciones de estos por aprender. A ello debemos sumar el hecho de que la clase gobernante, mientras tanto, mantenga atados, por medio de un sistema de incentivos, a gran parte de los agentes intelectuales para que estos continúen acrecentando el mito de la escuela como espacio democrático. Una dinámica propia de nuestra situación "pos-democrática", que diría Crouch (2005), la cual torna bastante improbable todo intento de cambio en los modos de educar.

De toda esta problemática se hace eco, entre otros muchos, Jiddu Krishnamurti, quien en sus escritos parte siempre de una especial preocupación por penetrar hasta la raíz misma de los principales problemas que caracterizan a nuestras sociedades actuales. En el presente trabajo nos centraremos en la obra El arte de vivir [Life Ahead: On Learning and the Search of Meaning], publicada por vez primera en 1963, donde Krishnamurti no solo realiza una síntesis de sus 
planteamientos principales, sino que además se dirige directamente a un lector joven, al que invita incesantemente a lo largo de sus páginas a intentar profundizar, como él mismo hace, en la naturaleza real de los problemas desde un cuestionamiento de los propios enunciados. El autor indio, consciente de la complejidad de nuestras sociedades y de la lucha frenética por mejorar nuestro estatus dentro de ellas, justifica la necesidad urgente de llevar a cabo estas reflexiones por el hecho de que, pese al conflicto constante que existe en la propia estructura social, no podemos vivir aislados como así plantea la disputa. Una circunstancia que es completamente desapercibida por una serie de gobernantes que, al no comprender la naturaleza real de los problemas, se hallan, según Krishnamurti, «muy confundidos, aunque digan que no lo están» $(1993,191)$.

El problema es bastante difícil, porque el deseo interno de ser la persona más rica o más poderosa, el impulso de ser alguien, depende, para su satisfacción, de la posesión de cosas, incluyendo alimento, ropas y albergue. Me apoyo en estas cosas a fin de enriquecerme internamente; pero en tanto me encuentre en este estado de dependencia, es imposible que sea rico internamente, porque esto último implica ser totalmente sencillo en la dimensión interna (Krishnamurti, 1993, 143).

Para Krishnamurti, en tanto que sigamos intentando poseer, acumular y trepar por la escalera del éxito, siempre existirá la figura del desamparado, por lo que el único modo de superar la terrible situación de injusticia que vivimos será, de entrada, cambiando el propio deseo de alcanzar la cima: «iNos preguntamos alguna vez por qué debemos tener lo que deseamos, cuando millones no tienen ni siquiera lo que necesitan?» $(1993,94)$. A este respecto el autor recuerda el hecho de que todas las reformas que se han llevado a cabo para intentar mejorar la situación tan solo han sido causas de reformas ulteriores y meras transferencias de poder y autoridad de un grupo a otro $(1993,7)$. Una circunstancia que, amparada en ese añejo "espíritu militar que nos vuelve obedientes", ha destruido poco a poco nuestras mentes en el sentido de que verdaderamente, como señalaran también Bourdieu y Passeron (2001), tan solo hemos desarrollado la capacidad de imitar a los otros, de copiar la propia necesidad de poseer, con el único fin de asegurar la autopreservación del sistema capitalista. De todo ello Krishnamurti extrae lo que según él debiera ser el fin último de la educación y, al mismo tiempo, la base de una justa y feliz sociedad: comprender lo que somos realmente.

En torno a esta última idea intentaremos establecer aquí una serie de consideraciones generales que nos ayuden a entender las implicaciones sociales del pensamiento de Krishnamurti sobre la educación -o viceversa-, para lo cual, sin querer limitarnos a ofrecer una mera reseña de uno de los trabajos más importantes de este autor, nos propondremos formular un conjunto de reflexiones que ayuden a afrontar los retos con los que se enfrenta la educación en el siglo Xxi. Procederemos a ubicar dicho asunto en el pensamiento y la biografía del autor para, a continuación, destacar algunas de sus implicaciones reales más directas. 


\section{La CUESTIÓN DE LA EDUCACiÓN EN EL PENSAMIENTO DE JidDU KRISHNAMURTi}

La enseñanza es la más noble de las profesiones, si es que puede siquiera ser llamada una profesión. Es un arte que requiere no solo logros intelectuales, sino una paciencia y amor infinitos. Ser correctamente educados es comprender nuestra relación con todas las cosas - con el dinero, con la propiedad, con la gente, con la naturaleza- en el vasto campo de nuestra existencia (Krishnamurti, 1993, 24-25).

Jiddu Krishnamurti nació en 1895 en Madanapalle, un pequeño municipio de Andhra Pradesh, estado del sureste de la India, y siendo muy joven sería absorbido por la Sociedad Teosófica bajo la tutela de Annie Besant y algunos otros teósofos ${ }^{1}$. Una serie de peculiares personalidades que intentaron hacerle creer que él era el elegido para ser el nuevo instructor del mundo al frente de una organización mundial llamada "La Orden de la Estrella». Una idea, pronosticada por aquellos teósofos, con la que el propio Krishnamurti rompería en 1929 poniendo fin a un período de hastío y confusión, desencadenado por la temprana muerte de su hermano Nityananda, con quien había estado formándose en Inglaterra ${ }^{2}$. Desde este preciso momento, Krishnamurti se dedicaría a difundir por todo el mundo un mensaje de conciliación basado en la ruptura con toda creencia, ideología o tradición, y la consiguiente liberación de la mente humana.

Jiddu Krishnamurti -filósofo, psicólogo, sociólogo, pedagogo, etc.- es considerado por muchos uno de los autores más originales y destacados del siglo Xx debido a la profundidad de su mensaje, anclado en la propia realidad del momento, pero, sobre todo, por su deseo predominante de hacer ver este como fruto del descubrimiento personal de cada individuo: en este proceso, según él, residiría la auténtica base para la liberación total del ser y el desarrollo de una nueva sociedad más justa. No debe sorprender, por tanto, que en estos tiempos convulsos y de gran desorden a todos los niveles, cuando todas las ideologías y religiones parecen haber demostrado un agotamiento en sus propias pretensiones, hayan sido muchas las personas que han encontrado en las enseñanzas de Krishnamurti una orientación vital idónea gracias a su carácter transdisciplinar y antidogmático. Un nuevo modo de entender la vida, un nuevo humanismo si se quiere, que es requerido con urgencia para encauzar las inminentes transformaciones que exige el mundo en que vivimos. Precisamente por ello, el tema de una nueva educación del ser,

1. Sobre su biografía véanse las obras de Mary LuTYens (1975, 1983, 1988, 1990, 1996), además de las de Pupul JaYAKAR (1986) y Roland Vernon (2002). También es interesante el documental titulado The Challenge of Change, dirigido por M. Mendizza y editado por la FKA. Consultado el 9 de marzo de 2015. http://www.jkrishnamurti.org/es/krishnamurti-teachings/view-video/the-challenge-of-changefull-version.php.

2. El 3 de agosto de 1929 Krishnamurti pronunció el célebre discurso por el que disolvería la Orden de la Estrella. Aquí puede leerse en su traducción española: J. KRISHNAMURTI, "Discurso en el Ommen Camp por el que se disuelve la Orden de la Estrella». Consultado el 9 de marzo de 2015. http:// www.jkrishnamurti.org/es/about-krishnamurti/dissolution-speech.php. 
como preámbulo de un nuevo ser por venir, disfruta en la obra de Krishnamurti de un lugar privilegiado.

En este sentido, debido a su especialmente audaz enfrentamiento con los problemas reales de nuestro día a día, no sería baladí aprovechar la ocasión para reivindicar el rico potencial de las ideas del pensador indio para el fértil terreno de la Filosofía de la Educación. Intentaremos, por ello, extraer aquí sus principales reflexiones sobre educación, a partir de esa particular mayéutica que Krishnamurti pone en juego, constituida siempre por dos momentos fundamentales: 1) una identificación clara de los problemas, sintetizada en una pregunta directa formulada por un agente externo (alumno, maestro, filósofo, etc.) y compartida por la mayoría de las personas; y 2) una batería de respuestas sencillas en forma de nuevas preguntas, surgidas directamente de una comprensión profunda de la naturaleza humana, cuya consecuencia no es otra que la de una sugerente invitación a indagar por uno mismo. Dos factores que, por otra parte, hacen de la lectura de Krishnamurti un proceso atractivo y abierto a todo tipo de lectores ${ }^{3}$.

Pero adentrándonos en el asunto de la educación en este autor, debemos advertir ante todo que este tema, pese a ser tratado explícitamente en varias de sus obras (cfr. Krishnamurti, 1984a, 1984b, 1996, 2013), es trabajado siempre en relación a una serie de factores internos y externos que de un modo u otro transforman y redefinen no solo los problemas trabajados, sino el propio concepto central de «educación». Por sintetizar en pocas palabras una serie de principios generales, debemos advertir que, como recordase el profesor Padmanabhan Krishna, exrector del centro educativo de Rajghat, perteneciente a la Fundación Krishnamurti de la India ${ }^{4}$, nos encontramos ante un concepto de educación basado en elementos tales como un cuestionamiento continuo de todo, una actitud receptiva y tolerante, un aprendizaje recíproco y un clima de armonía en el que se cuidan por igual los ámbitos físico, intelectual, emocional y espiritual. Se trata, además, de un posicionamiento que aboga por una reconciliación entre ciencia y religión, así como por una superación de la eterna dicotomía entre vicio y virtud en términos sentimentales. Todo ello, según Krishna, gracias a una reorganización de los procesos sociales

3. Krishnamurti dejó un gran legado en forma de charlas públicas, escritos, diálogos con profesores y estudiantes, científicos y renombrados religiosos, conversaciones con individuos, entrevistas en radio y televisión, así como cartas. Mucho de este material ha sido publicado en libros y en formatos audiovisuales y se encuentra alojado en diferentes sitios web de acceso totalmente gratuito. En el siguiente enlace existe una relación de vídeos sobre Krishnamurti alojados en Internet. Consultado el 9 de marzo de 2015. http://centrokrishnamurtimadrid.blogspot.com.es/2013/11/videos-jiddukrishnamurti-online.html.

4. En el siguiente enlace se encuentra una ficha académica del Prof. P. Krishna, así como una serie de textos breves propios traducidos al español. Consultado el 9 de marzo de 2015. http://www. pkrishna.org/spanish/. 
desde dentro hacia fuera, esto es, a partir del desarrollo profundo de la conciencia de uno mismo5.

Por otro lado, dentro de esta aproximación al asunto de la educación en Krishnamurti, resulta imprescindible aludir tanto a las propias escuelas diseñadas por él, como a las distintas fundaciones mundiales que puso en marcha, por constituir todas ellas ejemplos perfectos de aplicación directa de los principios mencionados, así como por sus evidentes consonancias con otras propuestas reformistas en educación. Hablamos en el primer caso de centros en los que, más que destacar desde el punto de vista académico, se fomenta el desarrollo del individuo en su totalidad, razón por la que, como afirma el autor en una de sus Cartas a las escuelas, "existen fundamentalmente para ayudar tanto al estudiante como al maestro a florecer en la bondad. Esto exige excelencia en la conducta, en la acción y en las relaciones. Este es nuestro propósito; esta es la razón de que se hayan creado estas escuelas: no para producir meros profesionales de carrera sino para dar origen a la excelencia del espíritu»(2013, 31-32).

Por una parte, los orígenes de estas escuelas se encuentran en el Centro de Educación de Rishi Valley, en Andhra Pradesh, evolución de un centro anterior fundado por Krishnamurti en 1928 e inspirado en la Universidad de Berkeley en California. Un lugar que, tras convertirse en la Fundación para la Nueva Educación, se constituyó finalmente como Fundación India Krishnamurti en 1970. El trabajo de la KFI abarca desde programas de educación, investigación y medio ambiente, siempre en el marco de las teorías de Krishnamurti, hasta otras actividades como la conservación y divulgación de la obra del autor ${ }^{6}$. Del mismo modo, junto a estas funciones debemos destacar la importancia otorgada a los aspectos medioambientales, que desde el principio han tenido un lugar destacado en las programaciones de las escuelas, y prueba de ello es que estas suelan ubicarse en lugares tranquilos y de gran belleza natural, enfocados al estudio y a la meditación. La importancia que daba Krishnamurti al espacio físico y al aprendizaje en un entorno natural encuentra su explicación en el interés del autor por favorecer la armonía entre las relaciones humanas y, al mismo tiempo, el desarrollo de una mente inquieta y creativa.

Tras el Rishi Valley, pero igualmente regido bajo la administración de la FKI, vendrían posteriormente otros centros como el Rajghat Besant School, el Vasanta College, otras escuelas en Bangalore y Chennai, así como un centro de atención para niños necesitados en Mumbai (Bombay). Asimismo, también son dignas de

5. Se trata de un breve texto en el que el Prof. P. Krishna se cuestiona sobre la existencia de una supuesta "educación krishnamurti». Un concepto que, según el profesor, de ser aceptado, tan solo aludiría al hecho de «vivir correctamente, no sólo aceptar la pregunta de alguien más y tratar de practicarla o repetirla». Consultado el 9 de marzo de 2015. http://www.pkrishna.org/spanish/krishnamurti_education_spanish.html.

6. Otra de las labores importantes de la FKI es la publicación, anualmente desde 1997, de la revista Journal of the Krishnamurti schools, que documenta gran parte de las ideas innovadoras que se llevan a cabo en sus centros. Consultado el 9 de marzo de 2015. http://www.journal.kfionline.org/. 
destacar las escuelas de Brockwood Park, en Inglaterra, y la del Happy Valley School en Ojai (California) 7 , por constituir dos ejemplos prácticos de los valores defendidos por Krishnamurti fuera de la India. En este último caso, por ejemplo, destaca la nómina de grandes intelectuales del momento que, junto a Krishnamurti, emprendieron el proyecto: la propia Annie Besant, Guido Ferrando, Aldous Huxley o Rosalind Rajagopal, entre otros ${ }^{8}$. Según se nos dice en el texto de presentación de la escuela, su objetivo no es otro que el de fomentar el «trabajar juntos en un espíritu de cooperación, no en la conformidad, tratando de cultivar y expresar lo que es excelente en cada uno"'. Un planteamiento que recuerda inevitablemente a casos como el de la célebre Yásnaia Poliana, fundada por Leon Tolstói en 1859, en el pueblo del mismo nombre. Uno de los primeros ejemplos de escuela libertaria y antirrepresiva, basado en la asimilación de un clima de cierto desorden, de enseñanza mutua entre profesores y estudiantes según las necesidades de estos últimos, y de trabajo cooperativo no competitivo (Tolstói, 2003).

En relación a las escuelas de la KFI (India), la KFA (EE. UU.) o la KFT (Inglaterra), debemos mencionar las charlas organizadas con motivo de las visitas periódicas a ellas llevadas a cabo por Krishnamurti. Unos encuentros en los que el pensador hacía preguntas directas a los alumnos sobre el concepto de educación, sobre qué opinaban respecto a la educación que recibían, sobre el comportamiento de los maestros, etc. Eran ocasiones muy especiales para toda la comunidad escolar, en las que Krishnamurti, lejos de aparentar ser un líder, insistía en que los alumnos intentasen comprender por sí mismos el mundo que les rodeaba. Al visualizar las grabaciones que existen de varios de estos actos, llaman profundamente la atención factores como la cordialidad del ambiente, la familiaridad con la que Krishnamurti se dirige a los alumnos o el grado de interés general de los temas tratados ${ }^{10}$. Del mismo modo, también se desarrollaban encuentros entre el fundador de estas escuelas y los maestros, fruto de los cuales nacieron obras como la titulada Pedagogía de la libertad, en la que se recogen diferentes conversaciones mantenidas en la escuela inglesa de Brockwood Park a lo largo del mes de septiembre de 1976 (Krishnamurti, 1996), o Krishnamurti y la educación, que recopila charlas con estudiantes y maestros de las escuelas del Rishi Valley y de Rajghat (Krishnamurti,

7. El Happy Valley es un proyecto que, todavía activo en nuestros días, se basa en la importancia de un entorno que favorezca el pleno desarrollo del potencial del estudiante, incluyendo en él tanto sus capacidades creativas como intelectuales. A este respecto resulta especialmente significativo el uso de la máxima "Aún aprendo», título del que es considerado el último de los grabados de Goya, como lema de la escuela.

8. En este enlace encontramos una breve reseña de cada fundador. Consultado el 9 de marzo de 2015. http://www.besanthill.org/about/history/founders/index.aspx.

9. Consultado el 9 de marzo de 2015. http://www.besanthill.org/about/history/index.aspx.

10. Muchas de estas charlas fueron filmadas y están disponibles en el canal oficial de Youtube de Jiddu Krishnamurti. Consultado el 9 de marzo de 2015. https://www.youtube.com/user/KFoundation/ featured. 
1984b). En ellas se debate en torno a conceptos claves como los de autoridad, libertad, aprendizaje, cooperación, etc.

Una serie de valores educativos fundamentales que, dentro del pensamiento general de Krishnamurti, se apoyan siempre de forma natural en aspectos tan variados como la posibilidad de una revolución psicológica, la naturaleza de la mente, la meditación, las relaciones humanas o la necesidad de un cambio social independiente de factores externos a la propia naturaleza de los individuos ( $c f r$. Krishnamuti y Bohm, 2001). Unas ideas que, en relación a la historia de las propuestas pedagógicas innovadoras, vendrían a dar una respuesta válida, según queremos defender aquí, a la necesidad de formar las identidades más deseables en la actualidad; o, dicho con otras palabras, a funcionar como una adecuada estrategia de cambio para afrontar los nuevos problemas de la enseñanza del siglo XxI. Un modelo, compartido por muchos a partir de los años sesenta, que, si bien rescata ciertos valores que han venido apareciendo aisladamente desde el comienzo mismo del pensamiento moderno (Ratke, Comenio, Rousseau), las propuestas románticas (Pestalozzi, Froebell) ${ }^{11}$ o, por supuesto, la Escuela Nueva ${ }^{12}$, consigue alcanzar en este contexto de la segunda mitad del siglo xx un alto grado de esplendor y profundidad a la luz del desarrollo de los medios de comunicación, la profusión de las democracias liberales y la incipiente conciencia de «aldea global» a nivel social.

\section{EL ARTE DE VIVIR}

Es entonces muy importante, mientras son jóvenes, que comiencen a comprender estos problemas y generen libertad dentro de sí mismos, porque entonces crearán un mundo nuevo, una nueva relación entre unos y otros. Y ayudarles a que hagan esto es, sin duda, el verdadero sentido de la educación (Krishnamurti, 1993, 168).

11. Nos referimos a principios como la defensa de la observación directa de la naturaleza, el protagonismo de los alumnos (paidocentrismo) o el conocimiento mediante la experiencia directa.

12. Sería interesante releer los casos de las escuelas citadas tras el análisis, no solo del precedente creado por Tolstói, sino también de otros ejemplos pertenecientes a los orígenes de la Escuela Nueva, tales como Abbotsholme School en Staffordshire (Inglaterra), L’École des Roches en Verneuilsur-Auvre (Francia) o las famosas escuelas campestres, "landerziehungsheimen", en ciudades como Ilsenburg, Haubinda o Bieberstein (Alemania). Todos ellos proyectos embrionarios de educación experimental que comparten una serie de principios comunes: paidocentrismo frente a logocentrismo; transversalidad frente a saberes disciplinarios; profesor como orientador y motivador; cooperación frente a competitividad; metodología activa basada en la experiencia; o una serie de alternativas a un sistema mecánico basado en la memorización; entre otros factores. Dentro de la Escuela Nueva, autores como María Montessori, Ovide Decroly, John Dewey, Célestin Freinet o Adolphe Ferrière, por citar algunos, intentarían establecer nuevos sistemas educativos complejos, basados en las más diversas metodologías, si bien en todos ellos la dignificación del niño y el respeto por la infancia funcionarían siempre como denominador común. 
La obra que en esta ocasión nos sirve como índice central de reflexión, El arte de vivir, fue concebida por Jiddu Krishnamurti en 1963 con la intención de dirigirse especialmente a los estudiantes. Una obra cuya elección aquí viene motivada precisamente por el hecho de funcionar como nexo entre las ideas generales del autor y la búsqueda de una difusión o un encuentro directo entre los jóvenes. Se trata de un texto que, como el resto de su producción, presenta un estilo claro y directo, dialogado, sin citas y sin barroquismo alguno. Concretamente, el poético título de El arte de vivir alberga una auténtica filosofía de vida plenamente humanista en el sentido en que defiende la más infinita expansión de las capacidades del ser humano. Un hecho que, pese a las evidentes connotaciones orientales que a él pueden asociarse, remite además a toda una tradición filosófica más próxima de lo que creemos: aquella, como explicaría Nehamas, basada en el modelo de "vida teórica» o "teorética», que empieza con Platón y encuentra en Foucault y su "cuidado de sín algunas de sus últimas consecuencias $(2005)^{13}$. La de Krishnamurti, en todo caso, constituye una obra en la que el autor indio vuelca todo su potencial epistemológico para invitar al cambio que este mundo necesita; cambio cuyo éxito, según Krishnamurti, dependerá de un único hecho: la transformación de la propia mente. De ahí que, como a continuación veremos, su propuesta educativa se centre principalmente en el descondicionamiento de los valores tradicionales y la apuesta por un desarrollo total del individuo. Dos propósitos que articulan todo un corpus teórico, complejo pero directo, que invita inexorablemente a ser llevado a la práctica.

En primer lugar, los planteamientos de Krishnamurti en sí mismos destacan por dos razones fundamentales: la primera, por ofrecer un modo posible y concreto de disolver los conflictos sociales; la segunda, por entender este modo como una forma de «ser» y "actuar» en el momento presente y no como un ideal utópico en tiempo futuro. Tomar conciencia de la urgencia de cambio en el ahora es, de hecho, la clave fundamental para comprender una filosofía ajena, como lo es la de Krishnamurti, a toda teleología. A partir de esta premisa, replantear la educación se convierte en una obligación pero, al mismo tiempo, en un proceso natural que no requiere demasiados instrumentos externos. Se trata, en realidad, de favorecer por todos los medios un descubrimiento interior que trascienda la materialidad del cuerpo y origine una auténtica revolución en el funcionamiento de la mente humana. Esta es la única manera de cultivar, más que un pensamiento crítico al uso, una sensibilidad crítica capaz de aunar percepción e inteligencia en un único proceso, conformado este, a su vez, por la simbiosis entre la mente superficial y la oculta (o inconsciente). Esta última, entendida por el autor como un factor más poderoso que la mente superficial, que funciona como depositaria del pasado

13. Desgraciadamente cualquier reflexión comparativa entre las ideas de un arte de vivir y de una filosofía como forma de vida desbordaría con mucho el propósito principal de este trabajo. Al respecto de este tema, no obstante, recomendamos la lectura de algunas obras de autores como el ya citado Alexander Nehamas (2005) o Pierre Hadot (1998, 2009, 2010). 
residual, pero capaz, también, de influir sobre el futuro (1993, 27). Un proceso de "investigación pura", situado en todo caso entre las dimensiones personal y social, en el que, por encima de las barreras ideológicas, teóricas o teológicas, se atiende a un todo integrado, "complejo" utilizando a Morin, al que nosotros mismos pertenecemos. De ahí que Krishnamurti apunte continuamente a la autocomprensión como el primordial requisito para la liberación.

En segundo lugar, y como consecuencia de lo anterior, debemos advertir que el concepto de educación de Krishnamurti, al suponer, como hemos dicho, un descubrimiento interior y exterior al mismo tiempo, se articula simultáneamente en tres dimensiones o registros que el autor distingue: "El cuerpo, las emociones y la mente -dice Krishnamurti- componen el ser humano total. A menos que vivan armoniosamente, el conflicto es inevitable» $(1993,19)$. Por un lado, en relación al primer registro, debemos decir que el cuerpo es para el autor el instrumento base de la mente y de su sensibilidad: dependiendo de la vitalidad y la salud que esta tenga, resultará el completo desarrollo de la persona. Por otro, Krishnamurti presenta los impulsos emocionales como un medio más potente que cualquier razonamiento intelectual. Según el autor, debemos ser sensibles a todo lo que nos rodea y no reprimir nuestras sensaciones, pues en ellas reside la respuesta generosa, «no calculada, que constituye la verdadera moralidad y conducta" $(1993,15)$. En tercer y último lugar, el desarrollo intelectual alude al particular proceso de la mente del cual dependerá que partamos de los hechos y no de las creencias que nos lega la tradición. Para Krishnamurti, en la conjunción correcta de estos tres registros estribará, en último término, que la mente comprenda su propio comportamiento e interprete o utilice la experiencia como un factor de liberación.

Por último, con el fin de expresar sintéticamente la filosofía educativa del autor, reorganizaremos las ideas principales que aparecen en El arte de vivir siguiendo un esquema propio en tres bloques fundamentales, correspondientes, según creemos, a las tres enseñanzas principales que encierra el libro: 1) no tener miedo a querer ser libres; 2) intentar comprender la verdad; y 3) vencer las barreras de la mente egocéntrica.

1) Como mencionábamos al principio, la educación tradicional se apoya en gran medida en el principio del miedo: se nos castiga al equivocarnos, al no repetir correctamente la respuesta y, como consecuencia de ello, se nos acostumbra a no hacer nada diferente porque, sencillamente, queremos ser tan respetables como creemos que son los adultos (Krishnamurti, 1993, 175). Para el autor, el temor es un factor fácil de introducir furtivamente en la escuela, siendo, no obstante, una de las principales barreras para la inteligencia. Donde hay miedo, insiste Krishnamurti, no puede haber iniciativa ni pensamiento creativo e, inconscientemente, perdemos la dignidad como seres humanos individuales. El miedo, según el autor, suele aparecer oculto bajo conceptos como respetabilidad o tradición y, en general, cuando nos limitamos a imitar y, por ende, a contentarnos con la mera representación de la realidad. El hábito, así, se torna garante del miedo y coarta la libertad de la mente deformando las ideas y torciendo el camino de los estudiantes. 
Contra el miedo, Krishnamurti se rebela: «Has de observar cómo tu mente está atada por todas estas cosas; ese es el principio de la inteligencia, la cual trae libertad» (1993, 67); este es el primer paso hacia la seguridad interior que precisa el alumno en su aprendizaje. Según el autor, hay que procurar que el alumno tenga el impulso o la exigencia de libertad, de modo que sea él mismo quien tenga la posibilidad de liberarse encontrando la respuesta por sus propios medios. De la superación del condicionamiento de la mente, dependerá de hecho que el alumno sea creativo y verdaderamente inteligente. Se trata, en definitiva, de no aceptar nada irreflexivamente solo por estar atemorizado por la autoridad y la disciplina, es decir, que no hay que tener miedo de querer ser libres, sino que, según Krishnamurti, se debe favorecer el continuo "descontento", entendido este como el estado en que la mente busca constantemente descubrir más: «Después de todo, ese es el sentido de la educación: ayudarles a que crezcan independientemente, de modo que estén libres de ambiciones y puedan descubrir su verdadera vocación. Es pues, responsabilidad de los maestros, del director, ayudarles a que sean inteligentes, a que no tengan miedo, de manera que puedan descubrir su verdadera vocación, su propio modo de vida, el modo como realmente quieren vivir y ganarse la subsistencia» $(1993,83)$.

2) En segundo lugar, como medio de satisfacer esa exigencia de libertad, Krishnamurti apuesta por la comprensión de la realidad en su más amplio sentido: "Comprender es ver directamente la verdad de algo, sin barrera alguna de palabras, prejuicios o motivos» $(1993,151)$. Una verdad oculta en cada acción, pensamiento o sentimiento, cuyo descubrimiento, sin embargo, depende no solo de un especial desarrollo de la atención, sino también de un fuerte componente de relatividad: «Si uno descubre que es codicioso -si lo descubre, no sólo porque algún otro se lo diga-, ese descubrimiento es la verdad, y esa verdad tiene su propia acción sobre nuestra codicia" (1993, 140). De modo que, como vemos, de la verdad depende el funcionamiento de la mente; detectar que esta está condicionada es la verdad en sí misma, en tanto en cuanto este hecho consiga liberar a la mente de sus limitaciones, consiga transformarla (cfr. Krishnamurti y Bohm, 2001, 17). A partir de aquí, toda verdad que esté más allá de la mente no será más que una ilusión. El propósito de la vida «es, en primer lugar, lo que tú haces de ella. Es lo que tú haces de la vida» $(1993,86)$. De ahí que: «El verdadero sentido de la vida -dice Krishnamurti- es permanecer internamente vacío, inocente, sin acumular demasiados conocimientos, sin creencias ni dogmas, sin el miedo a la autoridad; y ese estado de sencillez interna puede nacer sólo cuando comprendemos realmente cada experiencia de instante en instante, como un continuo» (1993, 147).

Para el autor, el conocimiento es necesario tan solo en un nivel funcional, como medio de cultivar la mente, pero no como un fin en sí mismo. "La inteligencia es el cuestionamiento del método» $(1993,51)$, aquel que han transmitido los maestros durante más de tres siglos. Para Krishnamurti, por ello, lo importante es el diálogo entre el maestro y el estudiante, no el sistema que fija una determinada manera de pensar $(1993,201)$. Entre las tareas del buen educador no está la de 
comparar las capacidades de sus estudiantes y producir evaluaciones que coarten las libertades de sus alumnos ${ }^{14}$, sino que, como dice el autor, la auténtica función del maestro no es otra que la de ayudar a comprender lo que es cada uno, para que el alumno «a partir de ahí empiece a descubrir cómo ser plenamente, más libremente, más expansivamente lo que es» (1993, 198). El correcto educador debe, además, aprender a trabajar codo con codo con la familia del alumno y, en general, no tener sentido alguno de la autoridad como tal, esto es, en su sentido coercitivo; se trataría más bien de un "orden sin autoridad" (Krishnamurti, 1996, 35). Un planteamiento que, como reconoce el propio Krishnamurti, requiere que para que el profesor realice bien su labor se ocupe únicamente de unos pocos alumnos.

3) En tercer y último lugar, Krishnamurti, como prerrequisito de todo lo anterior, apunta constantemente hacia la necesidad de romper con las barreras de la mente egocéntrica, aquella regida por el impetuoso deseo de «ser alguien». Una mente cultivada, según dice, en la noción de "deseo»: "Al desear, al anhelar algo, la mente crea un patrón y en ese patrón queda atrapada; y entonces se fatiga, se embota, se vuelve estúpida, irreflexiva» (1993, 101). De hecho, las causas de esa confusión generalizada a la que aludíamos al principio están muy claras para Krishnamurti: "Se hallan arraigadas en el "yo", que está deseando constantemente expandirse mediante la posesión, mediante el devenir, el éxito, la imitación; y los síntomas son los celos, la envidia, la codicia, el temor» $(1993,159)$. Según el autor, el "yo", fortalecido por la comparación, se apoya en el principio de orgullo, el cual nos otorga una satisfacción psicológica pero, al mismo tiempo, vanidad y engreimiento: al superar al de al lado se hace patente la importancia de uno mismo y, sin embargo, surgen el conflicto, la lucha y el dolor. Algo que, como recuerda Krishnamurti, también ocurre a escala social, al dividirnos como raza en grupos nacionalistas. Un proceso que conduce automáticamente «al deterioro, a la corrupción, al lento marchitar de la dignidad humana» $(1993,119)$.

Como sabemos, pensar en todas estas cuestiones es perturbador y, de hecho, los maestros tradicionales no han querido que sus alumnos pensaran en ellas realmente; ni siquiera han tenido paciencia para escuchar las preguntas que, de verdad, estos han querido y quieren hacerles. Los adultos en general, denuncia Krishnamurti, "están demasiado ocupados con sus propias disputas, con sus ambiciones y sus prejuicios, con sus debo y no debo de la moralidad y la respetabilidad" (1993, 175), y sin embargo son, junto a los padres, los referentes más directos de los jóvenes: en el escuchar, según Krishnamurti, está la transformación, la capacidad de hacer frente a la degeneración de la mente $(1995,29)$. Por todo ello, el deseo de ser alguien, de compararse, que incluye la necesidad de poseer cierta cantidad de propiedades, acaba conformando negativamente el núcleo mismo de

14. En la comparación -según KRISHNAMURTI, mera intelectualización sin amor-, se basa, por ejemplo, el éxito del libro, cuyo fin no es otro que cultivar la capacidad memorística, pero también la jerarquización entre conductor (docente) y conducido (discente). En palabras del autor, mediante la comparación "no hay iniciativa. No hay libertad ni para ustedes ni para el que conduce» (1993, 129). 
la mente, construyendo férreos muros alrededor de esta. Para Krishnamurti, de hecho, la inteligencia solo es posible cuando existe verdadera libertad respecto al sí mismo, al "yo", cuando no existe un centro acumulativo, sino que uno se conoce a sí mismo tal como es; "de ese conocimiento propio surge la inteligencia que puede afrontar la vida; esa inteligencia es creativa" (1993, 181). Y del mismo modo, "la belleza -dice Krishnamurti- es ese estado en el que la mente ha abandonado el centro del "yo", por la pasión de la sencillez" (1993, 25). Un elemento que, según el autor, obedece solo a la mente inocente, olvidada del yo, capaz de inquirir en lo desconocido: "Si somos abiertos, receptivos, sensibles tanto a lo feo como a lo bello, entonces veremos que ambos están llenos de significado, y esta percepción enriquece la vida» (1993, 131). De todo ello se deduce, en último término, que el remedio al proceso egocéntrico resida precisamente en comprender cómo se forma el "yo": "Comprendiendo los comportamientos del "yo" hay libertad respecto al "yo" " $(1993,112)$. Solo revirtiendo el proceso egocéntrico, el individuo puede desarrollarse plenamente, presentar una mente libre de prejuicios, comprender lo que le rodea, y, en definitiva, sentir «el perfume mismo de la vida, que es el amor», dice Krishnamurti (1993, 102).

El amor es justamente el trasfondo y el motor de estos tres principios generales. Para Krishnamurti, este elemento es principio y fin, un factor que no ha de usarse como medio político ni religioso, pues es algo que solo se brinda a sí mismo. De él depende el refinamiento de nuestra conducta y su calidad es «humildad, delicadeza, consideración, paciencia y cortesía. [...] El énfasis en esta calidad del amor libera a la mente del ensimismamiento de su ambición, en su codicia y en su afán adquisitivo" (1993, 17). La belleza, de hecho, es para el autor un estado del ser fruto del refinamiento interno que produce el amor, la capacidad de sentir todo lo que nos rodea, incluyendo los propios pensamientos. Esta es la «inteligencia del amor» (Krishnamurti y Bohm, 2001, 208). Según Krishnamurti, lo importante una vez más es averiguar qué hay realmente detrás de la palabra "amor»: "Cuando imaginamos lo que debe ser el amor y le damos ciertos motivos, creamos gradualmente un patrón de acción respecto del amor; pero eso no es amor, es meramente nuestra idea de lo que el amor debería ser» $(1993,100)$.

\section{LA INELUDiBle REVOLUCIÓN DE LA MENTE}

Como hemos intentado mostrar, las enseñanzas de Jiddu Krishnamurti destacan ante todo por ofrecer soluciones a una serie de problemas educativos reales desde una transformación del propio concepto de conciencia humana. Se trata, en este sentido, de un proyecto educativo que desde nuestro punto de vista trae consigo la particularidad de penetrar fácilmente, y sin ningún tipo de misticismo, en las profundidades de la conciencia y la existencia sin esquivar las vías convencionales 
del entendimiento. Podríamos afirmar, de hecho, que lo que el autor indio propone como estrategia de cambio es en verdad una revolución que parte de la propia forma de plantear los problemas, al intentar alterar o desconstruir, de algún modo, la naturaleza de sus distintas dimensiones. Una circunstancia que nos anima a establecer un último comentario que justifique el lugar que podría ocupar dicho posicionamiento dentro de un marco general de reflexión educativa e, indirectamente, la manera en que lo creemos válido para afrontar, después de medio siglo, los retos sociales a los que se enfrenta la educación actual.

Ante todo debemos comenzar recordando que, como apuntábamos en la introducción, el funcionamiento de la educación moderna ha estado marcado desde sus orígenes por un tipo de inercia que consolida, de algún modo, aquello que Collins llamase las «sociedades credencialistas» (1989). Un factor que, asociado a algunos otros, terminarían de explicar el fracaso de sus intentos de reforma: el aislamiento de la actividad docente, la formación insuficiente del profesorado, las expectativas de alumnos y familias, la incoherente organización del currículum escolar y de los centros, o las propias limitaciones de la práctica educativa (enseñanza transmisiva, protagonismo del examen, control represivo, etc.). Una serie de circunstancias que diseñan desde el poder un tipo de personalidad reproducible e incapaz de cuestionar los sistemas, mentes lineales que actúan al mínimo de sus posibilidades. Un panorama cuya única superación podría comenzar sencillamente por la subversión del propio concepto de «escuela» o, en este mismo sentido, por la reivindicación en nuestro caso de la noción deweyana de «educación» como proceso formativo que comprende toda una vida y, además, de la que depende la posibilidad de una sociedad verdaderamente democrática (Dewey, 2004).

Precisamente en Dewey, y sin poder demostrar -ni descartar- ningún tipo de contacto entre los autores, podríamos hallar los cimientos para leer las ideas de Krishnamurti dentro de un determinado marco de innovación educativa. El planteamiento central que propone este último, su ineludible revolución de la mente a partir de la indagación inquisitiva, resulta posible, de hecho, gracias a la existencia de unos férreos cimientos conformados por la fusión entre pensamiento y práctica o, en este caso, entre filosofía y educación. Si bien entre los siglos XV y XVI educación y filosofía, retomando los principios de la Antigua Grecia, anduvieron unidos en un solo ámbito (cfr. Hadot, 1998), no sería hasta cuatro siglos más tarde cuando Dewey propusiera una nueva simbiosis que intentase derrocar aquel tipo de educación moderna industrial, marcada por el enajenamiento moral y la separación de los saberes. Frente a la educación instrumentalizada y la filosofía sacralizada, es de hecho en el pragmatismo deweyano donde la verdad de las ideas es tal en la medida en que estas últimas afecten tanto al sujeto pensante como a su entorno natural ${ }^{15}$. Fue al fin y al cabo en el terreno de la educación donde Dewey

15. La filosofía, según DEwey, logra ejercer su verdadera función "cuando deja de ser un dispositivo para abordar los problemas de los filósofos, y se convierte en un método [...] para abordar los problemas de las personas» $(1917,3)$. 
introduciría sus propias concepciones filosóficas, pedagógicas y psicológicas, así como sus ideas sobre mejora social en términos de felicidad, bienestar y libertad: "La educación -dice el autor- es el laboratorio en que las distinciones filosóficas se vuelven concretas y son probadas" (Dewey, 1916, 329).

A partir de aquí, de este rotundo rechazo al dualismo cristiano-cartesiano, resulta difícil negar otra serie de conexiones tan evidentes -y pioneras- entre el pensamiento educativo de Dewey y el de Krishnamurti: desde el relativismo que ambos profesan hasta la concepción del pensamiento como constructor de la realidad presente, pasando por la reivindicación del gesto ordinario y la sabiduría práctica o la concepción del maestro como un participante más de la experiencia educativa, figura que garantiza, en su caso, el autodescubrimiento por parte del alumno y, por ende, su emancipación intelectual (cfr. Rancière, 2003). Una serie de principios que, como no podía ser de otra manera, encuentran su particular escenario en el ámbito de lo social: nuestro particular medio experiencial, colectivo e interactivo, en el cual, por el hecho de fluir con su propia dinámica, jamás debemos creernos terminados, inertes o completos. Una idea que, lógicamente, guarda mucha relación con la identificación, por parte de Krishnamurti, del proceso egocéntrico como germen de los conflictos sociales. La primacía del «yo» es el gran reto a superar y, en nuestro caso concreto, el eslabón que nos permite dar un paso más en la evolución de los planteamientos educativos que nos ocupan.

Una auténtica revolución de la mente es, de hecho, el punto de apoyo de toda una serie de teorías renovadoras que parten de lo que ha dado en llamarse la "psicología transpersonal» (Walsh y Vaughan, 1982, 1994). Una perspectiva que, en el terreno de la educación, preludiado por autores como Maslow (1963, 1982, 1998), recupera y afronta de lleno la concepción de una "mente superior» capaz de trabajar más allá de las redes conceptuales verdaderamente complejas, concretamente, hacia el terreno donde "lo uno" se funde con "el todo", el "yo" con la naturaleza a la que pertenece y, neurológicamente, las capacidades de un hemisferio cerebral con las del otro. Se trata, por tanto, de la reivindicación de una mente unificada que, al igual que en aquella idea de «reconocer que soy el mundo» de Krishnamurti (1996, 59), y lejos de implicar experiencias místicas teístas, defiende una estructura cognitiva de tipo lógico-intuitivo, una nueva identidad mundicéntrica y una completa horizontalidad reticular en términos de valores ético-sociales, curiosamente consonante con esa suerte de giro pragmático vital sobrevenido por la constitución de la sociedad tecnológica actual (cfr. Queraltó, 2002). Un conjunto de principios integradores que configuran ese tipo de "yo" que Wilber denominase "centauro": un estadio del ser que opera en el encuentro entre la noosfera y la biosfera (1997, 258), y por el que, en palabras de este autor, el individuo "comienza a ser transconsensual, transocial, transcolectivo y transadaptado" (1989, 97). Se trataría, pues, de un nuevo ser humano atento a lo que le rodea, poseedor de una conciencia que podríamos calificar como "hipersensorial» y que, de un modo transverbal, percibe su realidad alocéntricamente y consigue recuperarse completamente de las 
patologías de aquel «hombre unidimensional» que tan bien describiera y contextualizara Marcuse (2010).

Por todo ello, creemos que un lugar adecuado para las ideas de Jiddu Krishnamurti en el campo de la Filosofía de la Educación podría ser la bisagra entre los cimientos para el cambio de la Escuela Nueva, encabezada por Dewey, y las nuevas posibilidades que brinda una suerte de pedagogía o «educación transpersonal». En ambos casos, en los que la educación se legitima como herramienta de cambio social, encontramos un objetivo concreto definido, el de comprender sin miedo lo que somos realmente, y una vía para alcanzarlo: vencer los límites de la mente egocéntrica. Se trata por ello de un tipo de posicionamiento educativo que defiende una formación integral del individuo como única opción para trabajar con garantía de éxito en el ámbito de lo social, asignatura todavía pendiente en nuestros días: "La mente superficial -dice Krishnamurti-, al experimentar lo externo sin comprender lo interno, lo oculto, sólo ocasiona un conflicto más vasto y profundo" (1993, 28). Esta es la fórmula educativa que podemos extraer como conclusión, y que aglutina, como aquí hemos intentado mostrar, una serie de propuestas, de muy diferentes autores, pero siempre marcadas por la reivindicación de un modo de ser emocionalmente constructivo. Cabría recordar a este respecto la coincidencia de estas ideas con el desarrollo, en el campo de la psicología, de las teorías sobre la inteligencia emocional y social de Goleman (1996, 2006) y sobre las inteligencias múltiples de Gardner (1985). Elementos que, sin duda alguna, están ayudando a configurar progresivamente una nueva forma de entender la educación que tan solo tendría cabida en nuestras sociedades gracias a un pacto real por la educación, independiente de todo tipo de intereses políticos, económicos o religiosos. Una utopía que podría llegar a cumplirse próximamente gracias a las opciones positivas que brinda nuestro nuevo ecosistema comunicativo, y que acercaría, en este sentido, la consumación definitiva de aquella Ilustración «inacabada" como Habermas la entendiera (2008).

El propio Krishnamurti, que llegó a relacionarse por igual con científicos y religiosos de todo el mundo, nos dice, incluso sin palabras, que, dejando a un lado los ideales utópicos, las verdades dependen principalmente de las acciones: el autor, como hemos visto, no era un educador titulado, ni tampoco un hombre santo; fue sencillamente, y quizás como el resto de personas que han intentado e intentan mejorar la educación, un individuo pleno y consciente de su momento, que se dedicó fundamentalmente a trabajar por y para los demás.

\section{REFERENCIAS BIBLIOGRÁFICAS}

BOURDieu, P. y PASSERON, C. (2001) La reproducción: Elementos para una teoría del sistema de enseñanza. Madrid, Editorial Popular.

Brunet, I. y Altaba, E. (2010) Reformas educativas y sociedad de mercado. Barcelona, Laertes. 
Collins, R. (1989) La sociedad credencialista: Sociología histórica de la educación y de la estratificación. Trad. R. Lezcano. Madrid, Akal.

Crouch, C. (2005) Post-democracy. Cambridge, Malden; Massachussets, Polity Press.

Dewey, J. (1917) The need for a recovery of philosophy, Boydston, J. A. (ed.) (1980) The middle works, vol. 10 (1899-1924). Southern Illinois, University Press, Carbondale.

Dewey, J. (2004) Democracia y educación. Una introducción a la filosofía de la educación. Trad. L. Luzuriaga. Madrid, Morata.

Gardner, H. (1985) Frames of Mind: The Theory of Multiple Intelligences. New York, Basic Books.

Goleman, D. (1996) Emotional Intelligence: Why It Can Matter More Than IQ. New York, Bantam Books.

Goleman, D. (2006) Social Intelligence: The New Science of Social Relationships. New York, Bantam Books.

Habermas, J. (2008) El discurso filosófico de la modernidad. Trad. M. Jiménez. Madrid, Katz. Hadot, P. (1998) ¿Qué es la filosofía antigua? Trad. E. Cazenave. México D. F., Fondo de Cultura Económica.

Hadot, P. (2009) La filosofía como forma de vida: Conversaciones con Jeannie Carlier y Arnold I. Davidson. Trad. M. Cucurella. Barcelona, Alpha Decay.

Hadot, P. (2010) No te olvides de vivir: Goethe y la tradición de los ejercicios espirituales. Trad. M. Cucurella. Madrid, Siruela.

JAYAKAR, P. (1986) Krishnamurti: A biography. San Francisco, Harper \& Row.

Krishnamurti, J. (1984a) La educación y el significado de la vida. Trad. A. Clavier. México, Orión.

Krishnamurti, J. (1984b) Krishnamurti y la educación. Trad. A. Clavier. Barcelona, Edhasa.

KrishnamurTi, J. (1993) El arte de vivir. Trad. A. Clavier. Barcelona, Kairós.

KrISHNAMURTI, J. (1995) El camino de la inteligencia. Trad. FKI. Barcelona, Kairós.

Krishnamurti, J. (1996) Pedagogía de la libertad. Trad. FKL. Barcelona, Oasis.

KrishnamurTi, J. (2013) Aprender es vivir: Cartas a las escuelas. Trads. A. Clavier y J. Gómez Rodríguez. Madrid, Gaia.

Krishnamurti, J. y Bohm, D. (2001) Los límites del pensamiento. Trad. A. Clavier. Barcelona, Kairós.

LuTYEns, M. (1975) Krishnamurti: The Years of Awakening. Nueva York, Farrar, Starus \& Giroux.

LuTYENS, M. (1983) Krishnamurti: The Years of Fulfillment. Nueva York, Farrar, Starus \& Giroux.

LuTYens, M. (1988) Krishnamurti: the open door. Londres, John Murray.

LuTyens, M. (1990) The Life and Death of Krishnamurti. Londres, John Murray.

LUTYENS, M. (1996) Krishnamurti and the Rajagopals. California, FKA.

LYOTARD, J. F. (2012) La condición postmoderna: Informe sobre el saber. Trad. M. Antolín. Madrid, Cátedra.

Marcuse, H. (2010) El hombre unidimensional: Ensayo sobre la ideología de la sociedad industrial avanzada. Trad. A. Elorza. Barcelona, Ariel.

Maslow, A. (1963) Motivación y Personalidad. Trad. y pról. J. Ventosa. Barcelona, Sagitario.

Maslow, A. (1982) La amplitud potencial de la naturaleza humana. México, Editorial Trillas.

Maslow, A. (1998) El hombre autorrealizado: Hacia una psicología del ser. Trad. R. Ribé. Barcelona, Editorial Kairós. 
Nehamas, A. y Queraltó, R. (2005) El arte de vivir: Reflexiones socráticas de Platón a Foucault. Trad. J. Brioso. Valencia, Pre-textos.

Queraltó, R. (2002) Ética y sociedad tecnológica: pirámide y retícula. Argumentos de Razón Técnica, 5, 39-83.

RANCIÈRE, J. (2003) El maestro ignorante: Cinco lecciones sobre la emancipación intelectual. Trad. N. Estrach. Barcelona, Laertes.

Tolstói, L. (2003) La escuela de Yásnaia Poliana. Pról. A. Sanvicens. Editorial José J. de Olañeta.

Vernon, R. (2002) Star In the East: Krishnamurti, The Invention of a Messiah. Sentient Publications.

Walsh, R. y Vaughan, F. (eds.) (1982) Más allá del ego: Textos de Psicología Transpersonal. Trad. M. I. Guastavino. Barcelona, Kairós.

Walsh, R. y Vaughan, F. (eds.) (1994) Trascender el ego: La visión transpersonal. Trad. D. González. Barcelona, Kairós.

WilBer, K. (1989) El proyecto Atman. Trad. D. González. Barcelona, Kairós.

WilBer, K. (1997) Breve historia de todas las cosas. Trad. D. González. Barcelona, Kairós. 